\title{
Patterns of covert infection by invertebrate pathogens: iridescent viruses of blackflies
}

T. WILLIAMS

NERC Institute of Virology \& Environmental Microbiology, Oxford OX1 3SR, UK and ECOSUR, Tapachula, Chiapas, Mexico

\begin{abstract}
Recently, it has been recognized that blackfly populations may host two forms of infection by iridescent viruses (IVs); a covert (inapparent, nonlethal) form which was common in springtime populations in the River Ystwyth, Wales, and a patent (obvious, lethal) form which was rare. This study aimed to investigate the changes in frequency of the two types of infection in blackfly populations over the reproductive period of the flies, April-September 1992. Blackfly larvae sampled from three different sites along the river were bioassayed for the presence of covert IV infection. Of 870 larvae assayed, 17 were found to be infected. All the infected larvae appeared to be Simulium variegatum, the dominant species during the sampling period. IV infections were common in the spring (17-37\% depending on site) but appeared absent in the S. variegatum population for most of the summer months, reappearing again in the autumn (0-20\% infected). These fluctuations were concurrent with biotic and abiotic factors: elevated levels of covert infection occurred at low population densities, high water flow rates, low temperatures (and presumably slower growth rates), although it is not clear if any cause-and-effect relationship exists. Patent infections occurred immediately after the peak of covert infection in the spring, and again in the autumn. Virus characterization of isolates from covertly infected larvae showed that three distinct groups of isolates were present in the blackfly population. Isolates from the springtime populations were mostly variants of an isolate found in patently infected blackfly larvae in the 1970s (Aberystwyth IV). Isolates from the autumn populations were mostly variants of an isolate from a patently infected larva found in September the previous year. A third group comprised a single novel isolate which was detected in a covertly infected larva. The mechanisms by which IVs persist in blackfly populations remain unknown, although the role of alternative hosts is a possibility which needs to be studied.
\end{abstract}

Keywords: blackfly; fluctuations in incidence; inapparent infection; iridescent viruses; persistence; Simulium variegatum

Received 19 December 1994; accepted 27 March 1995

\section{Introduction}

In many animal populations there exist extended periods wherein conditions are not suitable for pathogen transmission, perhaps due to the host population failing to attain some critical threshold density or due to host dormancy, for example. During such periods pathogens must adopt strategies by which they can persist until conditions for transmission become favourable. The mechanisms by

Present address: El Colegio de la Frontera Sur (ECOSUR), Aptdo Postal 36, Tapachula 30700, Chiapas, Mexico. Tel.: (52) 96281077. Fax: (52) 96281015. which pathogens persist in host populations are still poorly understood in many systems (Grenfell \& Dobson, in press). One possible mechanism involves the pathogen persisting within the host by adopting nonlethal, e.g. latent, forms of infection. As the probability of transmission falls e.g. in low-density host populations, host-pathogen population models predict that pathogens which adopt strategies of host-exploitation which are not lethal to the host and which exploit vertical routes of transmission will be favoured over the lethal forms of disease (Anderson \& May 1981; Nowak 1991; Sasaki \& Iwasa 1991).

Such predictions are equally applicable to virulent 
insect pathogens which have been considered as biocontrol agents for insect pests and vectors. With a few exceptions (e.g. sex ratio distorting diseases of parasitic Hymenoptera) nonlethal infections may not produce overt symptoms in the insect host and where signs of disease do exist they may be subtle or difficult to detect (Sait et al. 1994b; Goulson \& Cory, in press). Consequently, the ecology of invertebrate pathogens usually focuses strongly on the behaviour and dynamics of the overt, lethal form of the disease. Therefore, due to difficulties in detection or due to a lack of interest in pathogens which do not appear to have biocontrol potential, covert (inapparent) infections have largely been neglected (Kelly 1985), despite their widespread occurrence in certain systems, e.g. many small RNA viruses of Drosophila and other insects (e.g. Dobos et al. 1991; Moore 1991). Invertebrate iridescent viruses (IVs) are also one such group.

IVs are nonoccluded icosahedral particles containing a dsDNA genome of $140-200 \mathrm{kbp}$ in size. The patent form of IV infection appears as a stunning opalescent coloration throughout the body of the host, usually an insect or crustacean. Paracrystalline arrays of virus particles in infected host tissues interfere with the passage of light and result in the characteristic iridescence, the colour of which is dependent on particle size and spacing (Klug et al. 1959; Hemsley et al. 1994). The patent disease is invariably lethal, but in most host populations, the incidence of these dramatic infections is minuscule. Consequently, IVs are not currently considered as useful agents for pest control. In an isopod-IV system, where transmission occurs via cannibalism of infected conspecifics, the patent lethal disease is the only recognized form of infection (Grosholz 1992). However, in another system, nonlethal covert IV infections of blackfly larvae (Diptera: Simuliidae) were demonstrated at levels of up to $c$. $30 \%$, many orders of magnitude greater than the patent disease (Williams 1993). Covert IV infections are not believed to be latent in the general sense used for viruses: latent viruses may integrate into the host genome or exist as naked nucleic acid in host cells which show few or no signs of infection until the virus is activated (see Hughes et al. 1993 for an insect virus example). Rather, the fact that covert IV infection can be transmitted to alternative hosts suggests that they exist as particles within host cells but at a very low density. Precisely which host tissues harbour covert IV infections are unknown although cells lining the midgut have been suspected (Glare 1992). IV isolates from both the covert (nonlethal) and the patent (lethal) infections exhibited a marked degree of genetic variability; no two isolates appeared identical and, with one exception, all appeared as variants of an original patent isolate discovered in blackflies at the same location in the 1970s (Batson et al. 1976; Williams 1993; Williams \& Cory 1993). Reference will be made to these isolates during the course of this study as marked similarities among the various isolates from covert and patent infections of blackfly larvae became apparent. The route of transmission of these viruses in blackfly populations is not known (Kelly 1985; Ward \& Kalmakoff 1991).

Recently, changes have been proposed in the classification and nomenclature of IVs (Williams \& Cory 1994). The previous system of naming isolates according to the host and the sequence of discovery was shown to be no longer useful and an alternative nomenclature based on geographical origin of the isolate was proposed. Consequently, IV type 22 from Simulium sp. (Batson et al. 1976) was renamed Aberystwyth IV in accord with its discovery in the River Ystwyth near Aberystwyth, Wales, UK. The new system of nomenclature is used here.

Blackflies are haematophagous Diptera with aquatic juvenile stages. Eggs are laid on stones, trailing vegetation or directly in the water. First-instar larvae disperse downstream on strands of silk and attach to substrates (stones or aquatic plants) in fast flowing sections of the river. Larvae undergo $\approx 6$ instars before pupating in a silk tent. Adult flies emerge, mate and the female seeks a blood meal from a vertebrate host before returning to the river to lay eggs. In the River Ystwyth, simuliids over-winter mainly as larvae. Pupation occurs in the early spring and the first generation of larvae appear in early April. S. variagetum appears to have a number of generations annually probably three, but these generations are not discrete.

Because the original report of covert IV infection was limited to a single sample in the springtime Simulium populations, a complete study was undertaken to determine changes in the abundance of covert inféction for the whole reproductive period of the River Ystwyth blackfly populations. In particular, three questions were addressed:

1 Is this a single-host-single-virus interaction?

2 How does the incidence of covert IV infection change over the spring and summer months?

3 Can these changes be correlated with biotic factors such as host density, age structure, community structure or abiotic factors such as water chemistry or temperature?

\section{Materials and methods}

\section{Field sampling}

Simulium larvae were sampled at monthly intervals between April 1992 and September 1992 from the three sites previously used along the River Ystwyth, Wales, UK (map references given in Williams 1993). These were an upstream mountainous fast-flowing site near Blaenycwm, an intermediate site near Abermagwr and a tranquil downstream site near Pentre-llyn. These sites were $\approx 32 \mathrm{~km}, 13 \mathrm{~km}$ and $7 \mathrm{~km}$ from the river estuary, respectively. Water chemistry data for the study period were 
obtained from the National Rivers Authority (NRA) for three sites along the Ystwyth which corresponded to each of the sampling sites. In addition the NRA provided daily mean flow data for the river at Pont Llolwyn near to the downstream site (Pentre-llyn). At each sampling occasion 50 stones were selected at random at each site. The number of Simulium larvae on each stone was estimated and the area of the uppermost surface of the stone (over which the larvae attached) was measured and noted. Stones without larvae were not considered. This gave an estimate of the density of larvae per $\mathrm{m}^{2}$ of suitable substrate. The density of pupae was not recorded as simuliids tend to select sites with different flow characteristics for pupation compared to larval feeding sites (Crosskey 1990). Larvae of all sizes were collected en masse from stones using soft forceps and placed in an antibiotic solution $(10 \mathrm{mg} / \mathrm{mL}$ streptomycin and $10000 \mathrm{IU} / \mathrm{mL}$ penicillin) and transported back to the laboratory in insulated boxes. All samples were frozen and stored at $-20^{\circ} \mathrm{C}$. In May, June and September, c. 500 larvae of all instars were taken from Abermagwr and reared in the laboratory to check for the occurrence of patent IV infections. Patently infected larvae found during searches of each site during this period have already been reported by Williams \& Cory (1993).

\section{Bioassay to detect covert IV infections}

Bioassay methods generally followed those given previously (Williams 1993). Covert IV infections in Simulium were detected following injection of individual blackfly larval homogenates into a permissive lepidopteran which subsequently developed a patent infection. Briefly, 50 Simulium larvae from each sample were thawed and identified (Davies 1968; Crosskey 1991). The length of each larva was measured to an accuracy of $0.2 \mathrm{~mm}$ using a binocular dissecting microscope at $\times \mathbf{4 0}$ magnification. These larvae were chosen unsystematically in an attempt to select a subsample representative of the size and species distribution of the sample as a whole. First- and secondinstar larvae were not used due to difficulties in species identification of these stages. Each larva was individually homogenized in $130 \mu \mathrm{L}$ of antibiotic solution (above) and spun at $1500 \mathrm{~g}$ to pellet insect debris. Groups of 8-10 thirdinstar Galleria mellonella (Lepidoptera: Pyralidae) larvae were individually injected with $\approx 8 \mu \mathrm{L}$ of supernatant from each Simulium larva. This species is highly permissive to a large number of invertebrate IVs and has become the standard host used for producing large quantities of these viruses (Ward \& Kalmakoff 1991). G. mellonella larvae were reared on artificial diet at room temperature and periodically assessed for patent IV infections. If no overt disease had appeared by 21 days postinjection, the result was considered to be negative. Control larvae (S. equinum and $S$. erythrocephalum) taken from Seacourt Stream at Wytham,
Oxford were treated in the same way. No evidence has been found for IV infection in Simulium populations around Oxford, despite extensive studies (Unpublished data).

\section{Characterization of virus from covert infections}

Galleria mellonella larvae with patent IV infections were homogenized in sterile distilled water and debris pelleted by centrifugation at $1500 \mathrm{~g}$ for $5 \mathrm{~min}$. Virus in the supernatant was pelleted by centrifugation at $10000 \mathrm{~g}$ for $5 \mathrm{~min}$. DNA was extracted from the semipure virus sample using SDS and Proteinase $K$ followed by phenol-chloroform treatment and dialysis (Williams \& Cory 1993). IV DNA was treated with EcoRI or HindIII following manufacturers protocols (Boeringer) and subject to electrophoresis through $0.6 \%$ agarose in TBE buffer. Gels were photographed and then Southern blotted onto Hybond (0.45 $\mu \mathrm{m}$ ) membrane (Amersham) (Sambrook et al. 1989).

A probe was made comprising a pUC19 plasmid containing a 1.4-kb SalI fragment of the Aberystwyth IV major capsid protein (MCP) gene described by Cameron (1990). This plasmid plus $100 \mathrm{ng}$ of phage lambda DNA were nick-translated with $\alpha^{32} \mathrm{P}-\mathrm{dATP}$ to high specific activity and purified on a Sephadex G50 column. Initially, blots were prehybridized for at least $4 \mathrm{~h}$ at $37^{\circ} \mathrm{C}$ in hybridization buffer (50-mM HEPES, $0.02 \%$ Ficoll $400,0.02 \%$ bovine serum albumin, $0.02 \%$ polyvinylpyrrolidone, $0.1 \% \mathrm{SDS}$ ) with $50 \%$ formamide and $100 \mu \mathrm{g} / \mathrm{mL}$ of salmon sperm DNA followed by hybridization overnight under the same conditions. Blots were subject to stringent washes at $63^{\circ} \mathrm{C}$ twice for $1 \mathrm{~h}$ each, followed by autóradiography. Following this, blots were stripped in $0.4-\mathrm{M} \mathrm{NaOH}$ at $45^{\circ} \mathrm{C}$, neutralized in 200-mM Tris- $\mathrm{HCl}$ ( $\mathrm{pH} \mathrm{7.0)}, 0.1 \times$ SSC, $0.1 \%$ SDS and rinsed in $2 \times$ SSC. Blots were then prehybridized and hybridized as before but at a lower strin-

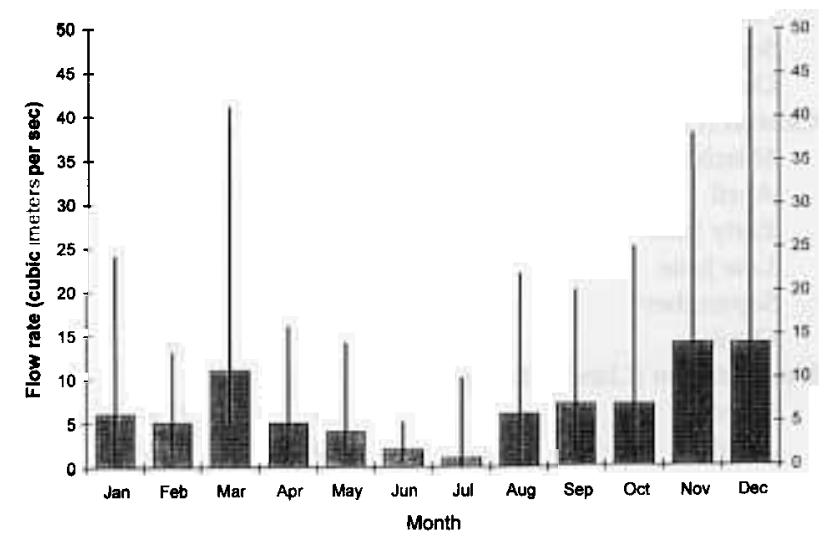

Fig. 1 Flow rate of the River Ystwyth during each month of 1992: daily mean [bars] with daily minimum and daily maximum for each month [lines]. 
gency: $20 \%$ formamide, $37{ }^{\circ} \mathrm{C}$ overnight, followed by washes in $2 \times$ SSC at $41^{\circ} \mathrm{C}$.

Relationships among isolates were further investigated by calculating the coefficient of similarity (Dice coefficient) (e.g. Grothues \& Tümmler 1991) for pairwise comparisons of isolate restriction profiles using the program Molmatch (University of Glasgow) which had been used for similar comparisons (Williams \& Cory 1994). Molmatch calculates $F$, the proportion of fragments of common size which two profiles share, using the formula $F=2 m /(a+b)$ (Nei \& Li 1979) expressed as a percentage. Where $m$ is the number of restriction fragments in common and $a, b$ are the total number of restriction fragments for each isolate. For the EcoRI comparisons, variation in fragment size across the gel was limited to $5 \%$. Due to the abundance of fragments of HindIII profiles, variation was limited to $2.5 \%$ except when compared to profiles published previously, for which the fragment size variation was limited to $5 \%$ following the Molmatch recommendations.

\section{Results}

\section{Blackfly sampling and river data}

For all the water samples, levels of dissolved oxygen were high (90-106\% saturation) and biological oxygen demand
(BOD) levels were low, reflecting the clean, fast-flowing nature of the river (Table 1). Levels of nitrogen consistently increased towards the downstream site. The concentration of metals (mostly zinc) increased sharply (x 10) between the upstream and central blackfly sampling sites (Esgair Wen bridge and Llanafar bridge) where the river flows through a disused mining area. Daily mean flow rates fell steadily through the spring and dropped to as little as $0.12 \mathrm{~m}^{3} / \mathrm{s}$ in July before increasing again in the autumn (Fig. 1). It became evident during sequential visits to the river that changes in the river flow rate had marked effects on the total area available for larval blackfly development at each site. By July, river flow was restricted to channels in the river bed at the central and downstream site which may be responsible for the sharp decline in the density of larvae recorded in the August sample.

Larval population densities increased by approximately two orders of magnitude at all sites between March and June before falling by an order of magnitude in late summer. The highest larval density was observed at the downstream site (Pentre-llyn) but blackfly distribution was patchy here. The central site (Abermagwr) actually supported larger populations of the larvae and for most of the sampling period had the highest larval densities.

In March, the dominant species was S. variegatum (62\%) followed by $S$. reptans $(27 \%)$. Larvae of $S$. agyreatum, $S$.

\begin{tabular}{|c|c|c|c|c|c|}
\hline & $\begin{array}{c}\text { Water } \\
\text { temp } \\
\left({ }^{\circ} \mathrm{C}\right)\end{array}$ & $\begin{array}{l}\text { Dissolved } \\
\mathrm{O}_{2}(\mathrm{mg} / \mathrm{L})\end{array}$ & $\begin{array}{l}\text { Total } \\
\text { BOD } \\
(\mathrm{mg} / \mathrm{L})\end{array}$ & $\begin{array}{l}\text { Total } \\
\text { oxidized } \\
\text { nitrogen } \\
(\mathrm{mg} / \mathrm{L})\end{array}$ & $\begin{array}{l}\text { Total } \\
\text { dissolved } \\
\text { metals } \\
(\mathrm{Cd}+\mathrm{Zn}+\mathrm{Pb}) \\
(\mathrm{mg} / \mathrm{L})\end{array}$ \\
\hline \multicolumn{6}{|c|}{ Upstream (Esgair Wen Bridge) } \\
\hline March & 9 & 11.8 & 0.6 & 0.48 & 0.017 \\
\hline April & 9 & 10.8 & 1.5 & 0.28 & 0.015 \\
\hline Early June & ND & 9.3 & 0.9 & 0.17 & 0.034 \\
\hline Late June & 15 & 9.2 & 0.5 & 0.07 & 0.030 \\
\hline September & 11 & 10.5 & 0.6 & 0.12 & 0.030 \\
\hline October & 10 & 10.2 & 1.2 & 0.16 & 0.006 \\
\hline \multicolumn{6}{|c|}{ Central (Llanafan Bridge) } \\
\hline March & 8 & 11.7 & 1.1 & 0.86 & 0.262 \\
\hline April & 10 & 11.6 & 1.0 & 0.86 & 0.426 \\
\hline Early June & ND & ND & 0.8 & 0.27 & 0.325 \\
\hline Late June & 15 & 9.8 & 1.6 & 1.00 & 0.355 \\
\hline September & 13 & 9.9 & 0.7 & 0.37 & 0.369 \\
\hline October & 12 & 9.7 & 0.5 & 0.64 & 0.449 \\
\hline \multicolumn{6}{|c|}{ Downstream (Llanilar Bridge) } \\
\hline March & 9 & 11.8 & 0.9 & 1.63 & 0.243 \\
\hline April & 9 & 11.5 & 1.6 & 2.12 & 0.368 \\
\hline Early June & ND & 9.1 & 1.1 & 0.68 & 0.319 \\
\hline Late June & 16 & 10.4 & 0.6 & 2.19 & 0.363 \\
\hline September & 14 & 9.5 & 0.5 & 1.22 & 0.383 \\
\hline October & 12 & 11.4 & 0.5 & 1.84 & 0.449 \\
\hline
\end{tabular}

Table 1 Details of water chemistry of the River Ystwyth during the sampling period in 1992 at three sites corresponding to the three blackfly sampling sites

$\mathrm{ND}=$ No data 
intermedium and S. aureum were also present. In April, Prosimulium sp. (probably $P$. tomosvaryi judging from the postgenal cleft) was observed at the central site ( $17 \%$ of sample) but for most of the study period, S. variegatum was dominant. In May, $S$. aureum appeared in the upstream sample $(6 \%)$ and in June S. aureum, S. intermedi$u m$ and $S$. agyreatum together comprised $34 \%, 8 \%$ and $4 \%$ of the bioassayed samples for the upstream, central and downstream sites, respectively. For the samples of July, August and September, S. variegatum was highly dominant and S. intermedium appeared at levels of $4-10 \%$ in September. S. variegatum larvae were distinctive in having a pale head capsule with virtually no markings, in contrast to the other species for which the head capsule markings were well developed, even in the middle instars. It is possible, however, that newly moulted larvae may have been mistaken for $S$. variegatum and so the proportion of other species in the samples may have been slightly underestimated.

Larvae taken from the Ystwyth in May, June and September showed good survival during laboratory rear- ing (c. $70 \%$ pupation). None of these larvae developed patent infections indicating that the covert form of infection is not an early stage of the patent disease which will develop later in the life of the insect. The same result was reported previously for larvae taken in April (Williams 1993).

\section{Bioassays for covert infection}

Of the 870 larvae bioassayed in this study, covert infections were detected in 17, all of which appeared to be $S$. variegatum. The striking result was that covert infections of blackfly larvae were not detected for most of the summer period, but appeared in appreciable levels $(8-37 \%)$ in spring and autumn samples (Table 2). For the April sample, bioassay results from the central site (Abermagwr) were combined with previous data: $2 / 20$ additional larvae were positive for covert infection (Table 2) and $8 / 30$ had been demonstrated positive by bioassay previously (total = 50 larvae) (Williams 1993). These two larvae were 6.2 and $6.8 \mathrm{~mm}$ in length, compared to a mean length of

Table 2 Summary of sampling data and bioassay results showing incidence of patent and covert infection during the sampling period in relation to published findings for the same period

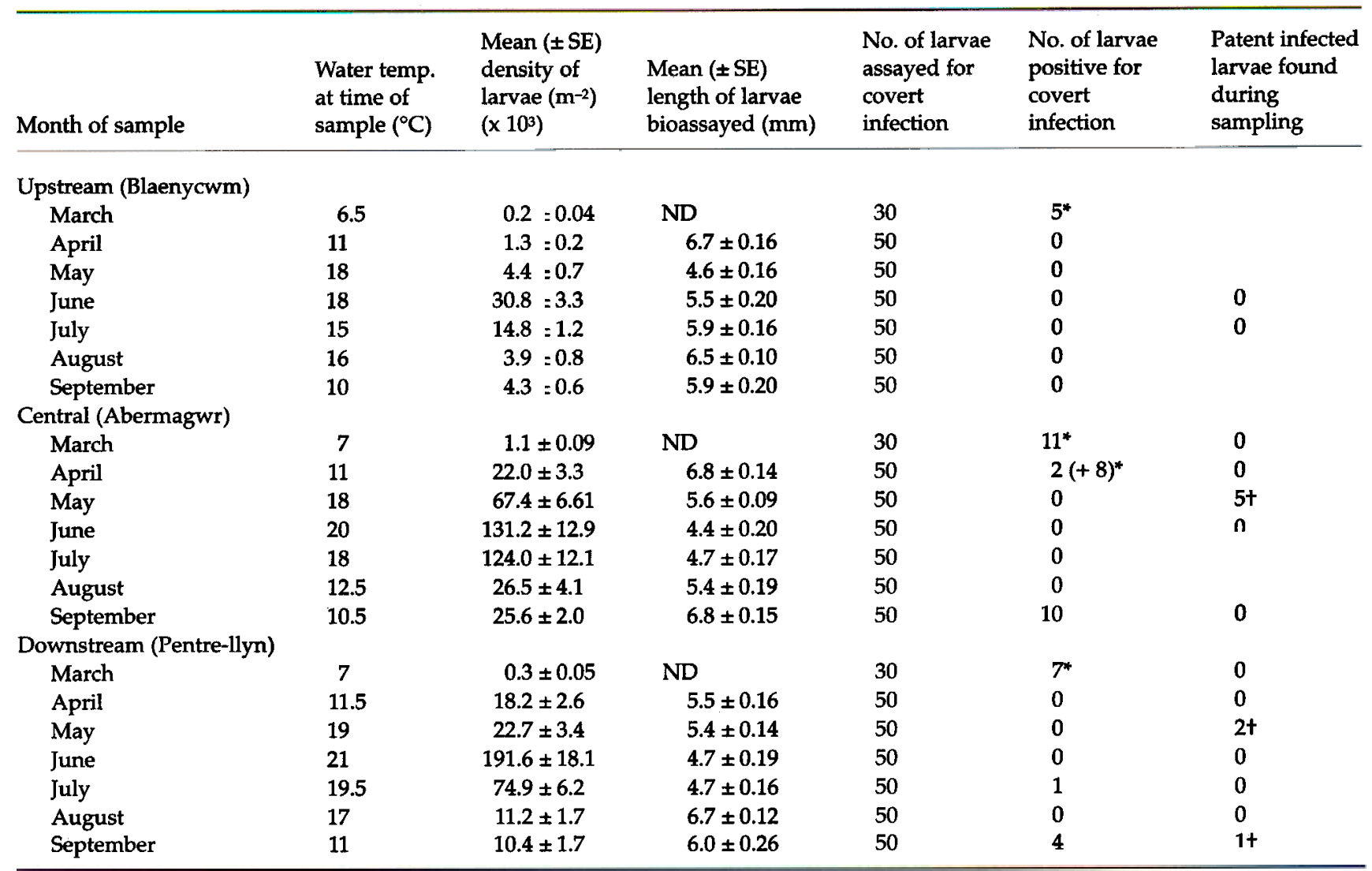

ND: No Data. *Data from PCR analysis of covert infection with sample size of 30 larvae (Williams 1993); +Patent infections described by Williams \& Cory (1993). 


\section{$\begin{array}{llllllllllllllllll}1 & 2 & 3 & 4 & 5 & 6 & 7 & 8 & 9 & 10 & 11 & 12 & 13 & 14 & 15 & 16 & 17 & 18\end{array}$}

(a)

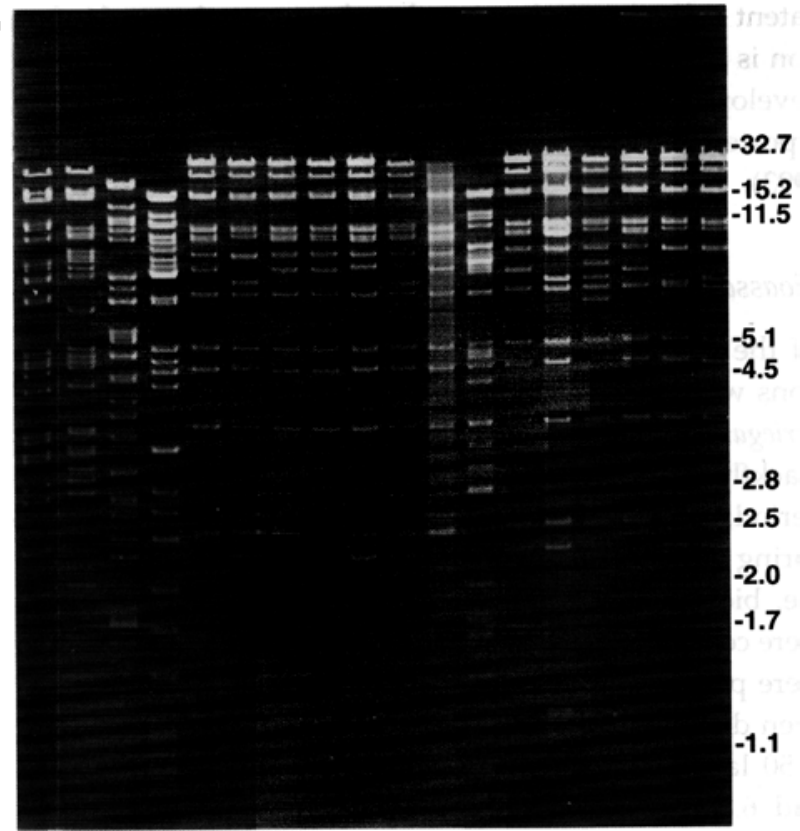

(c)

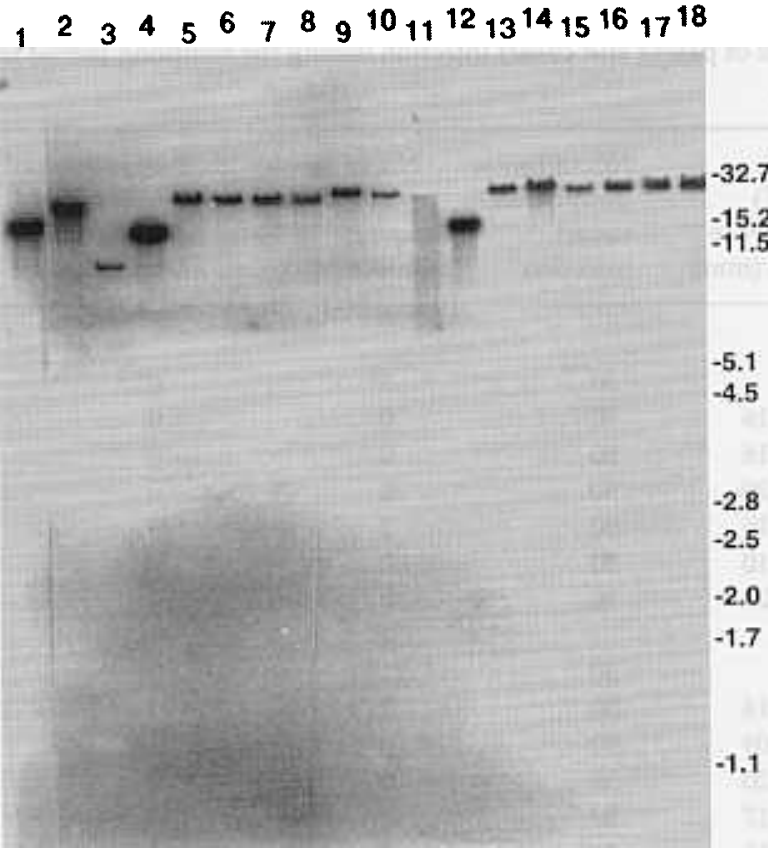

$6.8 \mathrm{~mm}$ for the sample as a whole. During the high population density periods of the summer (May, June, July), a single covertly infected larva was detected. This larva from the downstream site (Pentre-llyn) in July was $3 \mathrm{~mm}$ compared to the sample mean of $4.7 \mathrm{~mm}$. Covertly infected larvae from the September sample were sized between 6 and $7.6 \mathrm{~mm}(n=10)$ compared to the sample mean of $6.8 \mathrm{~mm}$ at the central site (Abermagwr) and $3.5-8 \mathrm{~mm}$ long $(n=4)$ at the downstream site compared to $6.0 \mathrm{~mm}$ for the sample mean. This range of sizes indicates that covert (b)

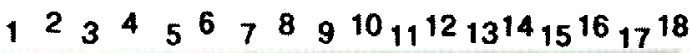

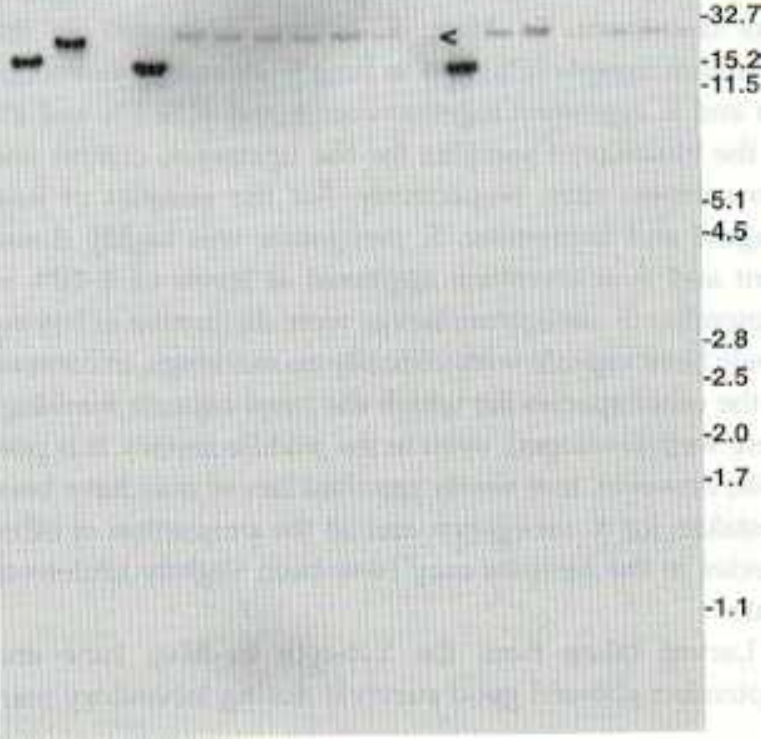

Fig. 2 (a) EcoRI restriction endonuclease profiles for IV isolates from covertly infected blackfly larvae during the study compared to Aberystwyth IV (Batson et al. 1976). Lanes of gel as follows, $1=$ Aberystwyth IV, 2-3 = Abermagwr April sample, 4 = Pentre-llyn July sample, 5-14 = Abermagwr September sample, 15-18 = Pentre-llyn September sample. (b) High stringency Southern blot of EcoRI gel (above) probed with major capsid protein gene fragment of Aberystwyth IV showing strong hybridization of probe only to variants of Aberystwyth IV. (c) Low stringency Southern blot of $E c o R I$ gel (above) reprobed with Aberystwyth gene probe showing hybridization to variants of September (Pentre-llyn like variants) and to a novel virus in lane 3 (Abermagwr, April). Arrowhead indicates the position of weak band for clarity.

infections were detected in all stages of the larvae tested (3rd to final-instar larvae). Control larvae from Oxford produced no viral infections in $G$. mellonella larvae indicating that $G$. mellonella cultures did not harbour inapparent viral pathogens and that bioassay procedures were sufficiently rigorous to prevent cross-contamination among samples. To assist in understanding the incidence of covert infection early in the season, Table 2 includes the data on covert IV infections detected by PCR in samples of 30 larvae from March 1992 (Williams 1993). The incidence of 


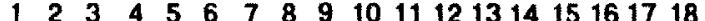

(a)

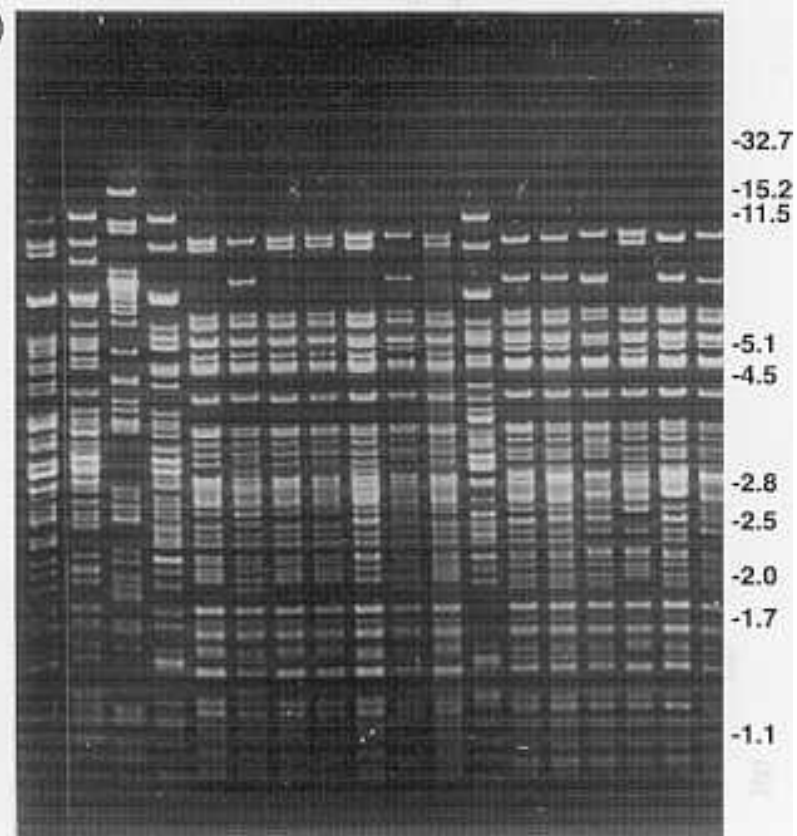

(c)

$1^{2} 3^{4} 5^{6} 7^{8} 9^{10} 11^{12} 13^{14}{ }_{15}^{16} 1^{18}$

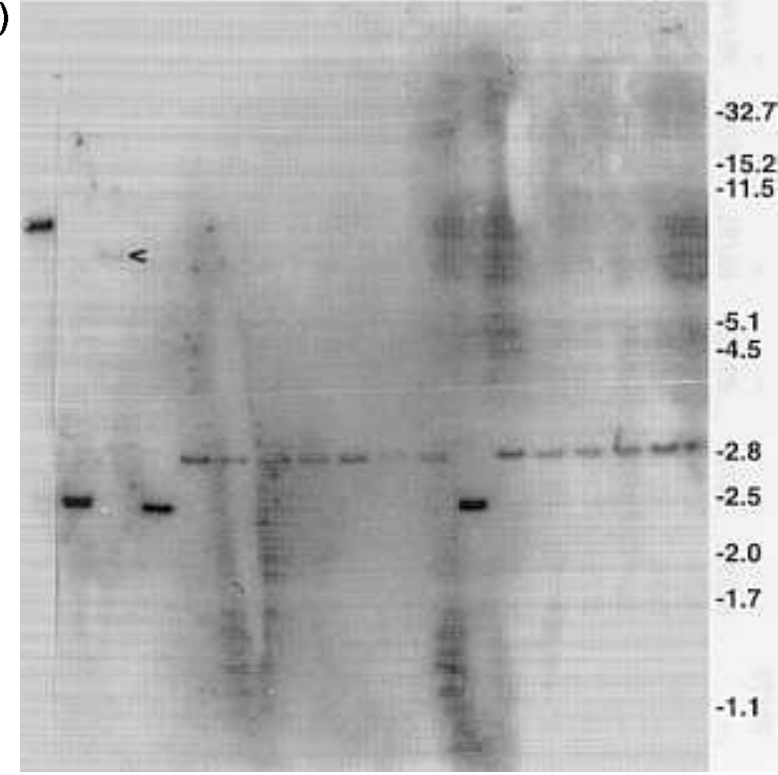

patently infected blackfly larvae found during the sampling period and reported by Williams \& Cory (1993) is also noted in Table 2.

\section{Characterization and comparison of covert IV isolates}

Restriction endonuclease analysis and Southern blot analysis of the various covert isolates detected in the bioassays gave very similar results for both HindIII and EcoRI enzymes. There was'a marked degree of genetic

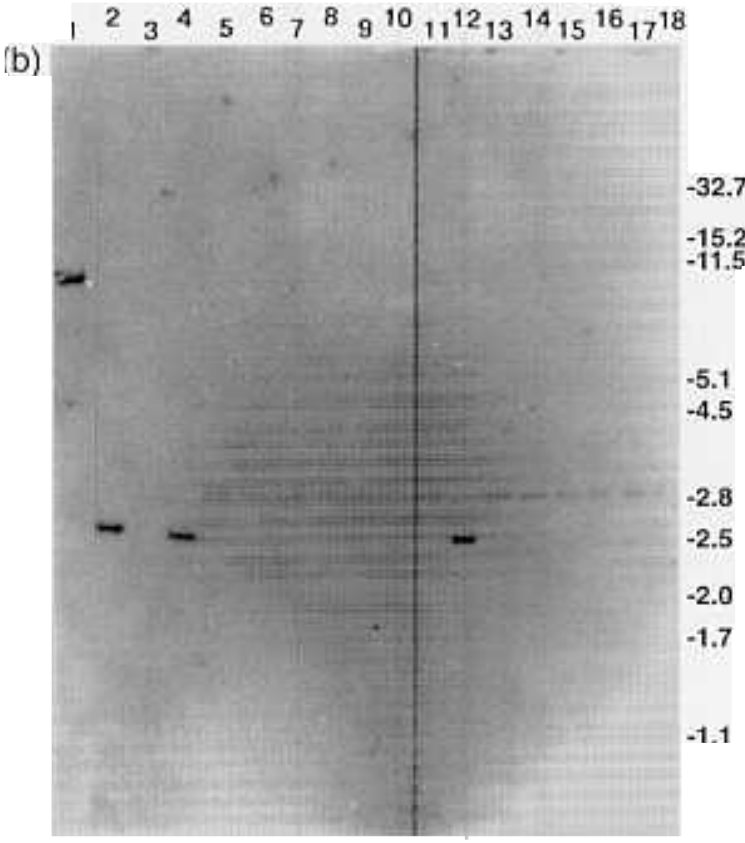

Fig. 3 (a) HindIII restriction endonuclease profiles for IV isolates from covertly infected blackfly larvae as given in Fig. 2: 1 = Aberystwyth IV, 2-3 = Abermagwr April sample, 4 = Pentre-llyn July sample, 5-14 = Abermagwr September sample, 15-18 = Pentre-llyn September sample. (b) High stringency Southern blot of HindIII gel (above) probed with major capsid protein gene fragment of Aberystwyth IV showing strong hybridization of probe only to variants of Aberystwyth IV. (c) Low stringency Southern blot of HindIII gel reprobed with Aberystwyth IV gene probe showing hybridization to variants of September (Pentre-llyn like variants) and very weak hybridization to apparently novel virus in lane 3 (Abermagwr, April) indicated by arrowhead. variation among isolates (Figs 2a and 3a). There were three isolates which appeared to be variants of Aberystwyth IV (Kelly et al. 1976): from Abermagwr April, Pentre-llyn July and Abermagwr September (lanes 2, 4, and 12, respectively, on the gels/blots). These isolates had clear restriction profile similarities to Aberystwyth IV (coefficients of similarity $70-82 \%$ ) and to one another (coefficients of similarity $70-75 \%$ ) but not to other isolates obtained in the study (Table 3). These Aberystwyth IV variants showed a high affinity for the Aberystwyth IV MCP gene probe, but all 
Table 3 Coefficients of similarity for pairwise comparisons of covert IV isolates obtained by bioassay of blackfly larvae and two isolates from patently infected blackfly larvae: Aberystwyth IV and I recent isolate from Pentre-llyn (September 1991) given as \% similarity values for EcoRI/HindIII profile comparisons. Coefficients $<70 \%$ not shown

\begin{tabular}{|c|c|c|c|c|c|c|c|c|c|c|c|c|c|c|c|c|c|c|}
\hline \multirow[b]{2}{*}{$\begin{array}{l}\text { Lane } \\
\text { of gel }\end{array}$} & \multirow{2}{*}{$\begin{array}{l}\begin{array}{l}\text { Aberyst- } \\
\text { wyth IV }\end{array} \\
1\end{array}$} & \multicolumn{2}{|c|}{ April Abermagwr } & \multirow{2}{*}{$\begin{array}{l}\text { July } \\
\text { Pentre- } \\
\text { llyn } \\
4\end{array}$} & \multicolumn{10}{|c|}{ September Abermagwr } & \multicolumn{4}{|c|}{ September Pentre-llyn } \\
\hline & & $\begin{array}{l}\mathrm{a} \\
2\end{array}$ & $\begin{array}{l}\mathrm{b} \\
3\end{array}$ & & $\begin{array}{l}a \\
5\end{array}$ & $\begin{array}{l}b \\
6\end{array}$ & $\begin{array}{l}c \\
7\end{array}$ & $\begin{array}{l}d \\
B\end{array}$ & $\begin{array}{l}\text { e } \\
\text { g }\end{array}$ & $\begin{array}{l}f \\
10\end{array}$ & $\begin{array}{l}\mathrm{g} \\
11\end{array}$ & $\begin{array}{l}\text { h } \\
12\end{array}$ & $\begin{array}{l}\mathrm{i} \\
13\end{array}$ & 14 & $\begin{array}{l}a \\
15\end{array}$ & $\begin{array}{l}\text { b } \\
16\end{array}$ & $\begin{array}{l}c \\
17\end{array}$ & $\begin{array}{l}\mathrm{d} \\
18\end{array}$ \\
\hline 1 & 100 & & & & & & & & & & & & & & & & & \\
\hline$?$ & $82 / 73$ & 100 & & & & & & & & & & & & & & & & \\
\hline 3 & - & - & 100 & & & & & & & & & & & & & & & \\
\hline 1 & $73 / 78$ & $75 / 72$ & - & 100 & & & & & & & & & & & & & & \\
\hline 5 & - & - & - & - & 100 & & & & & & & & & & & & & \\
\hline 5 & - & - & - & - & $87 / 87$ & 100 & & & & & & & & & & & & \\
\hline 7 & - & - & - & - & $100 / 96$ & $87 / 91$ & 100 & & & & & & & & & & & \\
\hline 3 & $\therefore$ & - & - & - & $94 / 94$ & $80 / 88$ & $94 / 98$ & 100 & & & & & & & & & & \\
\hline 3 & - & - & - & - & $92 / 86$ & $89 / 85$ & $92 / 90$ & $91 / 90$ & 100 & & & & & & & & & \\
\hline 10 & - & - & - & - & $87 / 86$ & $94 / 83$ & $87 / 82$ & $86 / 87$ & $89 / 82$ & 100 & & & & & & & & \\
\hline 11 & - & - & - & - & $97 / 90$ & $83 / 82$ & $97 / 94$ & $97 / 94$ & $89 / 91$ & $89 / 84$ & 100 & & & & & & & \\
\hline 12 & $70 / 75$ & $73 / 71$ & - & $70 / 73$ & - & - & - & - & - & - & - & 100 & & & & & & \\
\hline 13 & - & - & $=$ & - & $84 / 91$ & $84 / 91$ & $89 / 87$ & $86 / 81$ & $95 / 89$ & $95 / 94$ & $86 / 92$ & - & 100 & & & & & \\
\hline 14 & $-x$ & - & - & - & $84 / 90$ & $77 / 93$ & $72 / 84$ & $79 / 86$ & $82 / 88$ & $84 / 96$ & $84 / 91$ & - & $90 / 88$ & 100 & & & & \\
\hline 15 & -2 & - & - & - & $73 / 86$ & $82 / 87$ & $82 / 85$ & $79 / 82$ & $72 / 90$ & $82 / 94$ & $74 / 88$ & - & $84 / 86$ & $85 / 87$ & 100 & & & \\
\hline 16 & -2 & - & - & - & $94 / 93$ & $77 / 88$ & $87 / 90$ & $84 / 91$ & $87 / 96$ & $77 / 81$ & $84 / 98$ & - & $87 / 85$ & $87 / 83$ & $B 2 / 87$ & 100 & & \\
\hline 17 & -5 & - & - & - & $87 / 84$ & $77 / 87$ & $72 / 76$ & $74 / 77$ & $82 / 92$ & $82 / 81$ & $79 / 89$ & - & $81 / 91$ & $97 / 94$ & $\mathrm{~B} 2 / 90$ & $84 / 82$ & 100 & \\
\hline 18 & $-\frac{g}{q}$ & - & - & - & $82 / 88$ & $82 / 90$ & $72 / 80$ & $74 / 88$ & $82 / 94$ & $77 / 97$ & $79 / 88$ & - & $78 / 88$ & $95 / 84$ & $84 / 90$ & $81 / 79$ & $97 / 88$ & 100 \\
\hline Pentre-llyn* & - & & & & 87 & 91 & 93 & 84 & 87 & 88 & 91 & & 81 & 91 & 87 & 95 & 92 & 86 \\
\hline
\end{tabular}

"Coefficients of similarity of isolates from this study compared to previously published HindIII profiles of an isolate from a patently infected blackfly at Pentre-llyn (Sept. 1991) (Williams \& Cory 1993). 
differed from Aberystwyth IV in the size of the restriction fragment to which the probe hybridized. At high stringency, the probe hybridized to a 7-kb HindIII triplet fragment and a 15-kb EcoRI fragment of Aberystwyth IV, consistent with a previous study (Williams 1994) whereas for the variants, hybridization occurred to $2.4-\mathrm{kb}$ HindIII and $15-\mathrm{kb}$ or $19-\mathrm{kb}$ EcoRI fragments depending on the variant (Figs $2 b$ and $\mathbf{3 b}$ ).

With one exception (Pentre-llyn, April, lane three of gels) the remaining 13 isolates were all variants of a second (tentative) virus species (coefficients of similarity 76-98\% for HindIII and $72-100 \%$ for EcoRI, Table 3) and all displayed a common low affinity for the Aberystwyth IV MCP gene probe. Clear hybridization to the probe was only seen at low stringency in these variants (Figs $2 \mathrm{c}$ and $3 c$ ). The hybridizing fragments were slightly variable in size but were $\approx 2.8 \mathrm{~kb}$ for the HindIII and usually spanned two fragments of $c .24 \mathrm{~kb}$ and $c .21 \mathrm{~kb}$ of the EcoRI blots. By comparison of the HindIII profile of these variants with other profiles published previously it is evident that these are all variants of an isolate from a patently infected blackfly larva found at Pentre-llyn (downstream site) in September 1991 (Williams \& Cory 1993): coefficients of similarity of $81-95 \%$ (Table 2 ).

The single remaining isolate (Pentre-llyn April lane 3) showed no restriction profile similarities with any other isolates in this study, with other isolates from blackflies, or with any of the viruses which have been characterized in the same laboratory previously. Therefore, it cannot be a laboratory contaminant. This isolate also showed low affinity to the $\mathrm{MCP}$ gene probe which hybridized to a 10.6$\mathrm{kb} E c o R I$ fragment and very weakly to a $5.4-\mathrm{kb}$ HindIII fragment on the low stringency blots (Figs 2c, 3c). Consequently it appears that this is a novel virus from blackflies in the River Ystwyth.

\section{Discussion}

Monthly samples of blackfly larvae taken from the River Ystwyth, Wales, showed marked changes in the incidence of covert IV infection. The incidence of covert infection was initially high in March (previous data) but fell in April and remained extremely low $(<0.5 \%)$ during the summer months (May-August) when population densities were at their highest. Covert infections reappeared at appreciable levels $(5-30 \%)$ in low density over-wintering blackfly populations in the autumn. Because of the lack of winter sampling, the relationship between the generation sampled in September and the generation sampled the following spring is not known, although it is likely that larvae sampled in September would over-winter and emerge the following March, given the lack of blackfly reproduction in the winter months. Another intriguing aspect of the study was the observation that three distinct groups of virus iso- lates were present in covertly infected blackfly larvae during the sampling period. For two of these viruses, high levels of genetic variability were evident among variants. Both of these viruses have previously been isolated causing overt (lethal) disease in blackfly larvae in the Ystwyth. Nothing is known about the ability of the novel (third) virus to cause patent infections in blackflies. The role of spatial heterogeneity in the distribution of larvae was not addressed here but may be an additional factor of importance in the dynamics of the host-pathogen interaction as reported in other insect virus systems (Dwyer 1991). The bioassay procedures used were highly sensitive. Possibly less than 10 particles are required to initiate a patent infection in this host (Day \& Gilbert 1967), a level of detection comparable with PCR (Williams 1993). Moreover, bioassay has an advantage in that large quantities of the virus result when covert infections are detected (i.e. when patent infections develop in G. mellonella larvae).

This study aimed to answer three questions concerning fluctuations in the incidence of covert infections over time, the ability to correlate these fluctuations with biotic and abiotic factors and concerning the number of species involved in the host-virus interaction. Changes in the incidence of IV infection in blackflies were concurrent with changes in biotic and abiotic factors: elevated levels of covert infection occurred at low population densities, high water flow rates, low temperatures and presumably slower growth rates, as reflected in the larger larvae of the spring and autumn samples, although there are insufficient data for correlation. Actually, the study has raised more questions than it has answered. Whereas changes in the incidence of covert infection are well defined, the reasons behind such changes remain far from clear. High levels of covert infection in March and April preceded the observation of patently infected larvae in May (all of these isolates, covert and patent, were variants of Aberystwyth IV, bar one). Similarly, covert infections in September were all variants of an isolate causing patent disease found at Pentre-llyn in September of the previous year. There is a substantial part of the story still missing however; what happens during the winter months, wherein the Pentrellyn like variants of September disappeared and the Aberystwyth IV variants re-appeared the following spring? During the winter, the river becomes greatly swollen and sampling would be both difficult and hazardous. At the outset of the study, the winter was not considered to be particularly interesting to sample, a dormant period for the over-wintering stages, therefore no such sampling was performed. This was unfortunate in retrospect.

Whereas previous work based on a springtime sample from the Ystwyth (Williams 1993) had suggested that the system was a simple $S$. variegatum - Aberystwyth IV interaction, further sampling showed this to be at least a one 
host - and possibly a three virus system. The specific status of each type of virus detected here cannot be determined until proper characterization and comparative studies are performed. One possible explanation for the observed patterns of infection in this study is that other aquatic species, possibly of completely different invertebrate taxa such as Crustacea, are involved in the persistence of iridescent viruses in the river and in the transmission of these infections to susceptible blackfly populations at different times of the year. Various sympatric aquatic insect species (e.g. caddis flies as Simulium predators) were bioassayed for covert IV infections during the course of the study, but not in large numbers and not in a systematic way, rather out of curiosity to find out if any alternative lines of study were worth developing. None proved positive for IV infection. However, the results of this study suggest that systematic sampling and appraisal of possible alternative host species in the river could be worthwhile. Such studies may reveal additional layers of complexity in the blackfly IV interaction, or may confirm that the viruses in this system persist and are transmitted within blackfly populations alone.

It appears that in this blackfly system patent and covert infections are not linked with distinct classes of iridescent viruses. Rather it seems probable that there exists some triggering mechanism, be it 'environmental or innate, which switches the common covert form of infection into the patent (lethal) form (Williams 1993). In baculoviruses, stress factors such as food quality, crowding, coinfection by heterologous viruses are commonly cited as supposed switches for the expression of latent infections (Entwistle \& Evans 1985; Hughes et al. 1993). It is not known if covert infection has a detrimental effect on the viability or reproduction of blackflies. In laboratory experiments with a lepidopteran-baculovirus system, the presence of virus has been shown to alter both the magnitude and periodicity of host population cycles (Sait et al. 1994a). It is assumed that this was due to sublethal effects of virus infection on moth development rate and reproductive capacity which were measured separately (Sait et al. 1994b).

Because of the great interest in pathogens for insect biocontrol, wherein high virulence is the most desired feature, very few studies address dynamics of host-parasite systems wherein the infection is mostly innocuous. Understanding the ecology of invertebrate pathogens means recognizing that duality may exist in the strategy of host exploitation by the virus. Such duality is particularly evident in iridescent virus infections of blackflies.

\section{Acknowledgements}

I am very grateful to the following people who have assisted me during the course of this study, namely: Tim Carty for his work supplying Galleria larvae, Chris Hatton for his quick photographic service, Simão Vasconcelos, Rosie Hails, Pablo Liedo, and
Geraldine Gillespie for their diverse help, and Sonya Watts and Chris Rowlands of the National Rivers Authority, Wales for the water data.

\section{References}

Anderson RM, May RM (1981) The population dynamics of microparasites and their invertebrate hosts. Philosophical Transactions of the Royal Society, B291, 451-524.

Batson BS, Johnston MRL, Arnold MK, Kelly DC (1976) An iridescent virus from Simulium sp. (Diptera; Simuliidae) in Wales. Journal of Invertebrate Pathology, 27, 133-135.

Cameron IR (1990) Identification and characterization of the gene encoding the major structural protein of insect iridescent virus type 22. Virology, 178, 35-42.

Crosskey RW (1990) The Natural History of Blackflies. Wiley, Chichester.

Crosskey RW (1991) A new checklist of the blackflies of Britain and Ireland, with geographical and type information (Diptera: Simuliidae). Entomologist's Gazette, 42, 206-217.

Davies L (1968) A key to the British species of Simuliidae (Diptera) in the larval, pupal and adult stages. Scientific Publications of the Freshwater Biological Association, 24, 1-125.

Day MF, Gilbert N (1967) Number of particles of Sericesthis iridescent virus required to produce infections in Galleria mellonella. Australian Journal of Biological Sciences, 20, 691-693.

Dobos P, Nagy E, Duncan R (1991) Birnaviridae. In: Viruses of Invertebrates (ed. Kurstak E), pp. 301-314, Marcel Dekker, New York.

Dwyer G (1991) The effect of density, stage structure and spatial structure on the transmission of an insect virus. Ecology, 72, 559-547.

Entwistle PF, Evans HF (1985) Viral control. In: Comprehensive Insect Physiology, Biochemistry and Pharmacology (eds Kerkut GA, Gilbert LI), pp. 347-412, Pergamon Press, Oxford.

Glare TR (1992) Further electron microscopic evidence of inapparent viral infections in the midgut of the New Zealand grass grub, Costelytra zealandica White (Coleoptera: Scarabidae). Journal of Invertebrate Pathology, 59, 206-209.

Goulson D, Cory JS (in press) Sublethal effects of baculovirus infection in a lepidopteran. Biological Control, in press.

Grenfell B, Dobson AP (eds) (in press) Wildlife Disease Dynamics Oxford University Press, Oxford.

Grosholz ED (1992) Interactions of intraspecific, interspecific and apparent competition with host-pathogen population dynamics. Ecology, 73, 507-514.

Grothues D, Tümmler B (1991) New approaches in genome analysis by pulsed-field gel electrophoresis: an application to the analysis of Pseudomonas species. Molecular Microbiology, 5, 2763-2776.

Hemsley AR, Collinson ME, Kovach WL, Vincent B, Williams T (1994) The role of self-assembly in biological systems: Evidence from iridescent colloidal sporopollenin in Selaginella megaspore walls. Philosophical Transactions of the Royal Society, $B, 345,163-173$.

Hughes DS, Possee RD, King LA (1993) Activation and detection of a latent baculovirus resembling Mamestra brassicae nuclear polyhedrosis virus in $M$. brassicae insects. Virology, 194, 608-615.

Kalmakoff J, McMillan N, Davison S (1990) Insect iridescent viruses type 9 and type 16. In: Molecular Biology of Iridoviruses (ed. Darai G), pp. 113-136. Kluwer Pubs., Boston. 
Kelly DC (1985) Insect iridescent viruses. Current topics in Microbiology and Immunology, 116, 23-35.

Klug A, Franklin RE, Humphreys-Owen SPF (1959) The crystal structure of Tipula iridescent virus as determined by Bragg reflection of visible light. Biochimica Biophysica Acta, 32, 203-219.

Moore NF (1991) Identification, pathology, structure and replication of insect picornaviruses. In: Viruses of Invertebrates (ed. Kurstak E), pp. 287-299. Marcel Dekker, New York.

Nei M, Li WH (1979) Mathematical model for studying genetic variation in terms of restriction endonucleases. Proceedings of the National Academy of Sciences, 76, 5269-5273.

Nowak M (1991) The evolution of viruses. Competition between horizontal and vertical transmission of mobile genes. Journal of Theoretical Biology, 150, 339-347.

Sait SM, Begon M, Thompson DJ (1994a) Long term population dynamics of the Indian meal moth, Plodia interpunctella and its granulosis virus. Journal of Animal Ecology, 63, 861-870.

Sait SM, Begon M, Thompson DJ (1994b) The effects of a sublethal baculovirus infection in the Indian meal moth, Plodia interpunctella. Journal of Animal Ecology, 63, 541-550.

Sambrook J, Fitsch EF, Maniatis T (1989) Molecular Cloning: a Laboratory Manual. 2nd edn, Cold Spring Harbour Press, New York.

Sasaki A, Iwasa Y (1991) Optimal growth schedule of pathogens within a host: switching between lytic and latent cycles.
Journal of Theoretical Biology, 39, 201-239.

Ward VK, Kalmakoff J 1991 Invertebrate Iridoviridae. In: Viruses of Invertebrates (ed. Kurstak E), pp. 197-226, Marcel Dekker, New York.

Williams T (1993) Covert iridovirus infection of blackfly larvae. Proceedings of the Royal Society, B, 251, 225-230.

Williams T, Cory JS (1993) DNA restriction fragment polymorphism in iridovirus isolates from individual blackflies (Diptera: Simuliidae). Medical and Veterinary Entomology, 7, 199-201.

Williams T, Cory JS (1994) Proposals for the new classification of iridescent viruses. Journal of General Virology, 75, 1291-1301.

Williams T (1994) Comparative studies of iridoviruses: Further support for a new classification. Virus Research, 33, 99-121.

Since 1990 I have been studying various aspects of the ecology of viral diseases in invertebrate populations at the IVEM, Oxford with particular emphasis on iridescent viruses. I am currently involved with the Iridovirus subgroup of the International Committee for the Taxonomy of Viruses and have made suggestions for changes to the taxonomy and nomenclature of these viruses. I hope to be able to continue this work and to develop additional lines of biocontrol-related research in my new job here at ECOSUR, Mexico. 